J. Dairy Sci. 95:3139-3148

http://dx.doi.org/10.3168/jds.2011-4298

(C) American Dairy Science Association ${ }^{\circledR}, 2012$.

\title{
Comparison of the sulfur hexafluoride tracer and respiration chamber techniques for estimating methane emissions and correction for rectum methane output from dairy cows
}

\author{
C. Muñoz, ${ }^{*} \dagger^{1}$ T. Yan, ${ }^{*}$ D. A. Wills, ${ }^{*}$ S. Murray, ${ }^{*}$ and A. W. Gordon‡ \\ ${ }^{*}$ Agri-Food and Biosciences Institute (AFBI) Agriculture Branch, Hillsborough, Co. Down, BT26 6DR, United Kingdom \\ †Instituto de Investigaciones Agropecuarias (INIA) Remehue, Osorno, Región de Los Lagos 5290000, Chile \\ ‡AFBI Biometrics Department, Belfast, BT9 5PX, United Kingdom
}

\begin{abstract}
The objectives of the present study were to compare the sulfur hexafluoride $\left(\mathrm{SF}_{6}\right)$ and respiration chamber techniques for measuring methane $\left(\mathrm{CH}_{4}\right)$ emissions from dairy cows and to determine the proportion of $\mathrm{CH}_{4}$ that is released through the rectum. Data used were derived from 20 early lactation dairy cows in a $2 \times$ 2 factorial design study for 4 periods with $6 \mathrm{wk} /$ period. The 4 treatment diets consisted of grass silage and 2 levels of concentrate (30 and 60\% dry matter basis), with or without yeast supplement. At the end of each period, $\mathrm{CH}_{4}$ emissions were measured simultaneously using the $\mathrm{SF}_{6}$ and respiration chamber techniques when cows were housed in chambers. The $\mathrm{SF}_{6}$ technique was also used when cows were housed in digestibility units (barn location) before and after respiratory chamber measurements (chamber location). The simultaneous measurements in chamber location revealed that $\mathrm{CH}_{4}$ emission estimates by the $\mathrm{SF}_{6}$ technique were similar to those by the respiration chamber technique in the first 3 periods, although the $\mathrm{SF}_{6}$ estimates were significantly higher in period 4 . The regression of all data from the 4 periods demonstrated a linear relationship between the $\mathrm{SF}_{6}$ and respiration chamber measurements for total $\mathrm{CH}_{4}$ emissions $\left(\mathrm{g} / \mathrm{d}, \mathrm{R}^{2}=0.69\right)$ and for $\mathrm{CH}_{4}$ emissions per unit of milk yield $\left(\mathrm{g} / \mathrm{kg}, \mathrm{R}^{2}=0.88\right)$, and a quadratic relationship for $\mathrm{CH}_{4}$ emissions per unit of dry matter intake $\left(\mathrm{g} / \mathrm{kg}, \mathrm{R}^{2}=0.64\right)$. The $\mathrm{CH}_{4}$ emissions from the rectum were calculated as the difference between $\mathrm{CH}_{4}$ estimates from the $\mathrm{SF}_{6}$ technique when cows were housed in respiratory chambers and barn locations, which was $3 \%$ of the total $\mathrm{CH}_{4}$ emissions from the mouth, nostrils, and rectum. The $\mathrm{SF}_{6}$ estimates in the chamber location accounted for all sources of emis-
\end{abstract}

Received February 23, 2011.

Accepted January 17, 2012.

${ }^{1}$ Corresponding author: camila.munoz@inia.cl sions, whereas those in the barn location, like that in grazing conditions, did not include $\mathrm{CH}_{4}$ emission from the rectum. Therefore, the $\mathrm{SF}_{6}$ measurements for grazing cattle should be adjusted for $\mathrm{CH}_{4}$ emissions from the rectum (3\% of total). We conclude that the $\mathrm{SF}_{6}$ technique is reasonably accurate for estimating $\mathrm{CH}_{4}$ emissions.

Key words: methane, sulfur hexafluoride tracer technique, respiration chamber, dairy cow

\section{INTRODUCTION}

Accurate and reliable measurements of methane $\left(\mathrm{CH}_{4}\right)$ emissions from individual animals have traditionally been made using respiration chambers. However, they require trained animals, restricted animal movement, and have a high labor input and expense (Johnson et al., 2007), and their results might not be extrapolated to free-ranging animals (Pinares-Patiño and Clark, 2008). A technique that makes use of the inert tracer gas sulfur hexafluoride $\left(\mathrm{SF}_{6}\right)$ has been developed for estimating $\mathrm{CH}_{4}$ emission rates from ruminants under grazing conditions (Johnson et al., 1994).

In recent years, some studies have examined the validity of the $\mathrm{SF}_{6}$ tracer technique for estimating $\mathrm{CH}_{4}$ emissions. Most studies with beef cattle and sheep found statistical agreement between $\mathrm{CH}_{4}$ emissions estimated by the $\mathrm{SF}_{6}$ and respiration chamber techniques (Ulyatt et al., 1999; Boadi et al., 2002; McGinn et al., 2006; Johnson et al., 2007; Pinares-Patiño et al., 2011), although not all (Wright et al., 2004; Pinares-Patiño et al., 2008a). The accuracy of this technique for lactating dairy cows is less clear, as McCourt et al. (2008) indicated that $\mathrm{CH}_{4}$ measured using the $\mathrm{SF}_{6}$ technique was $75 \%$ of that measured using respiration chambers, whereas Grainger et al. (2007) reported a ratio of $102 \%$ between the estimates from the $\mathrm{SF}_{6}$ and respiration chamber techniques. In both studies, the technique comparison was done with dairy cows in mid lactation. No comparisons between $\mathrm{SF}_{6}$ and respiration chambers 
have been made at different stages of lactation, especially for early lactation cows with high $\mathrm{CH}_{4}$ emissions.

In grazing ruminants, the $\mathrm{SF}_{6}$ technique estimates $\mathrm{CH}_{4}$ exiting through the mouth and nostrils, but not through the rectum. In an early study conducted in sheep using an isotope tracer method, Murray et al. (1976) reported that the magnitude of $\mathrm{CH}_{4}$ excreted through the rectum was less than $2 \%$ of the total $\mathrm{CH}_{4}$ produced by an animal, despite $13 \%$ of the total $\mathrm{CH}_{4}$ being produced by the hindgut. Consequently, it is expected that $\mathrm{CH}_{4}$ estimates measured using the $\mathrm{SF}_{6}$ technique should be slightly lower than actual total $\mathrm{CH}_{4}$ emissions. However, little information is available for correction of $\mathrm{SF}_{6}$ measurement for $\mathrm{CH}_{4}$ emissions from the rectum of grazing cattle.

The objectives of the present study were to 1) compare the $\mathrm{SF}_{6}$ tracer technique with the respiration chamber technique for measuring $\mathrm{CH}_{4}$ emissions from individual dairy cows and 2) determine the proportion of $\mathrm{CH}_{4}$ that is excreted through the rectum compared with total enteric $\mathrm{CH}_{4}$ emissions.

\section{MATERIALS AND METHODS}

The work described in the present paper was conducted at the Agri-Food and Biosciences Institute (AFBI), Hillsborough, UK, in accordance with the requirements of the UK Animals (Scientific Procedures) Act 1986 and with the approval of the AFBI (Hillsborough) Ethical Review Group.

\section{Animals, Experimental Design, and Diets}

The data used in the present study were obtained from a 2 (concentrate level) $\times 2$ (yeast supplement) factorial design study with 4 periods (6 wk/period). Twenty early lactation dairy cows $(56 \pm 25 \mathrm{~d}$ postpartum) were used, which were of 3 genotypes (4 Norwegian, 4 Norwegian $\times$ Holstein-Friesian, and 12 HolsteinFriesian) and had various parities (4 primiparous and 16 multiparous cows). Nutritional treatments consisted of 2 levels of concentrate (30 and 60\%, DM basis), without or with yeast supplement at $0.5 \mathrm{~g} / \mathrm{d}$ (Levucell SC20; Lallemand SAS, Blagnac Cedex, France). There was a 3 -wk interval between periods 1 and 2, 2 and 3 , and 3 and 4 , so each cow was on treatments for 33 wk. The experimental design aimed to maximize the range of feed intake and, thus, $\mathrm{CH}_{4}$ emissions, which was expected to increase the accuracy of validation of the $\mathrm{SF}_{6}$ technique.

Throughout the present study, cows were offered ad libitum their experimental diets once daily in the morning as a TMR of grass silage and concentrates. They were allowed free access to water, and milked twice daily at approximately 0700 and $1600 \mathrm{~h}$. The grass silages had pH 3.9 and contained 28.2\% DM, 18.4 MJ of gross energy $/ \mathrm{kg}$ of $\mathrm{DM}$, and $13.2 \% \mathrm{CP}, 46.4 \% \mathrm{NDF}, 30.1 \%$ $\mathrm{ADF}$, and $8.6 \%$ ash on a DM basis. Concentrates were based on soybean meal, rapeseed meal, barley, corn, soybean hulls, and citrus pulp.

During each period, animals were housed as a single group in a cubicle accommodation for the first $30 \mathrm{~d}$. Afterward, cows were placed in individual stalls in digestibility units for $4 \mathrm{~d}$, with feed intake recorded and $\mathrm{CH}_{4}$ emissions estimated using the $\mathrm{SF}_{6}$ technique (described later) during the final $3 \mathrm{~d}$ (barn location before chamber measurements). They were then transferred to indirect open-circuit respiration chambers where they stayed for $4 \mathrm{~d}$, with feed intake recorded and $\mathrm{CH}_{4}$ emissions measured simultaneously by both the $\mathrm{SF}_{6}$ and respiration chamber techniques (chamber measurement described later) during the last $3 \mathrm{~d}$ (chamber location). After completion of chamber location measurements, cows were returned to the digestibility units for the final $4 \mathrm{~d}$ of each period, with feed intake recorded and $\mathrm{CH}_{4}$ emissions estimated using the $\mathrm{SF}_{6}$ technique during the final $3 \mathrm{~d}$ (barn location after chamber measurements). There were 2 respiration chambers and cows were paired based on their calving dates and treatment allocation at the beginning of each period to progress through the measurement sequence. At the end of periods 1, 2, and 3 , cows were returned to the group for a 3 -wk interval before the start of the next feeding period.

\section{$S_{6}$ Tracer Measurements}

The technique originally developed by Johnson et al. (1994) was used to determine individual daily $\mathrm{CH}_{4}$ emissions using the $\mathrm{SF}_{6}$ tracer gas. A week before the beginning of the first $\mathrm{CH}_{4}$ measurements, a brass permeation tube containing $\mathrm{SF}_{6}$ gas of known release rate was placed in the rumen of each cow. The $\mathrm{SF}_{6}$ release rate and expected lifetime for each tube were calculated using prefilling weight of $\mathrm{SF}_{6}$ gas and a 6-wk serial of weights measured at a controlled environment $\left(39^{\circ} \mathrm{C}\right)$. The release rates of $\mathrm{SF}_{6}$ tubes ranged from 4.10 to $6.39 \mathrm{mg} / \mathrm{d}$, with a mean of $5.39 \mathrm{mg} / \mathrm{d}$, and the corresponding values for lifespan were 374 to 540 and 456 d, respectively. During the course of periods 1 to 4 , $\mathrm{CH}_{4}$ measurements were carried out when tubes were deployed in the rumen of cows between 7 and $262 \mathrm{~d}$, with an average of $29,98,161$, and $231 \mathrm{~d}$ for periods 1 , 2,3 , and 4 , respectively.

Before and after being in the respiratory chamber (barn location), on the first day of $\mathrm{CH}_{4}$ measurements, a head collar was placed on each cow sustaining a gas 
collection tube running from just above the animal's nostrils to a gas collection canister. The gas collection tube connected one after the other, an airline $(6.35-\mathrm{mm}$ diameter), a $15-\mu \mathrm{m}$ filter, and a capillary tube with an evacuated polyvinyl chloride (PVC) canister. As the vacuum within the canister began to dissipate, a sample of air from around the cow's mouth and nostrils was collected. The restriction given by the capillary tube allowed a flow rate of around $0.60 \mathrm{~mL} / \mathrm{min}$, which filled the canister to around 0.5 atmosphere pressure over a 24 -h period. For the chamber location, as the air inside the chamber was completely mixed by an air-conditioning system, the gas-collection canister was located in the back of each chamber with the end of the airline placed inside the air duct that exits the chamber, through which air was circulated toward gas analyzers.

The $\mathrm{SF}_{6}$ and $\mathrm{CH}_{4}$ concentrations in the sampling canisters were determined by GC (Varian 3600 GC; Varian Inc., Palo Alto, CA) fitted with a 6 Port Valve 200 and plumbed to a 1041 injector. Samples were injected through a 1-mL sample loop at a flow rate of $30 \mathrm{~mL} /$ min using nitrogen as the carrier gas. All samples were analyzed in duplicate. After injection, the sample was split in 2 (50:50) for the determination of $\mathrm{CH}_{4}$ and $\mathrm{SF}_{6}$ simultaneously. The $\mathrm{CH}_{4}$-packed column (1.2-m length and 2-mm i.d.; Varian Inc., Walnut Creek, CA) was a stainless steel Porapak N (80-100 mesh), whereas the $\mathrm{SF}_{6}$-packed column (1.8-m length and 2-mm i.d.; Varian Inc.) had a molecular sieve 5A (45-60 mesh). The operating and conditioning temperatures of the injector and columns were both 70 and $120^{\circ} \mathrm{C}$, respectively. A flame ionization detector was used for the detection of $\mathrm{CH}_{4}\left(250^{\circ} \mathrm{C}\right.$; JVA Analytical, Dublin, Ireland), whereas the $\mathrm{SF}_{6}$ concentration was measured using an electron capture detector $\left(300^{\circ} \mathrm{C}\right.$; JVA Analytical). The gas chromatograph was calibrated weekly using 3 gas standards (Scott-Marrin Inc., Riverside, CA). Standards were gas mixtures of 10,150 , and $300 \mathrm{ppt} \mathrm{SF}_{6}$ with 10 , 100 , and $300 \mathrm{ppm} \mathrm{CH}_{4}$, corresponding to low, medium, and high concentrations of each gas, respectively. The medium standard was run at the beginning and end of each day.

Methane emissions $\left(\mathrm{CH}_{4} \mathrm{Q} ; \mathrm{L} / \mathrm{d}\right)$ were calculated from the measured $\mathrm{SF}_{6}$ and $\mathrm{CH}_{4}$ concentrations sampled by the canisters $\left(\mathrm{SF}_{6} \mathrm{C}\right.$ and $\left.\mathrm{CH}_{4} \mathrm{C}\right)$, background $\mathrm{SF}_{6}$ and $\mathrm{CH}_{4}$ concentrations $\left(\mathrm{SF}_{6} \mathrm{~B}\right.$ and $\left.\mathrm{CH}_{4} \mathrm{~B}\right)$, the predetermined release rate of $\mathrm{SF}_{6}$ from the permeation tubes $\left(\mathrm{SF}_{6} \mathrm{Q}\right)$, and the molecular weight $(\mathrm{MW})$ of the gases according to the following equation:

$$
\begin{gathered}
\mathrm{CH}_{4} \mathrm{Q}=\left(\mathrm{CH}_{4} \mathrm{C}-\mathrm{CH}_{4} \mathrm{~B}\right) /\left(\mathrm{SF}_{6} \mathrm{C}-\mathrm{SF}_{6} \mathrm{~B}\right) \\
\times \mathrm{SF}_{6} \mathrm{Q} \times \mathrm{MW} \text { of } \mathrm{CH}_{4} / \mathrm{MW} \text { of } \mathrm{SF}_{6} .
\end{gathered}
$$

The unit for $\mathrm{CH}_{4}$ emission as $\mathrm{L} / \mathrm{d}$ was then converted to $\mathrm{g} / \mathrm{d}$. When applying the $\mathrm{SF}_{6}$ technique in the chambers, air sampled at the chamber inlet was used to determine $\mathrm{SF}_{6} \mathrm{~B}$ and $\mathrm{CH}_{4} \mathrm{~B}$ concentrations.

After the completion of measurements in period 4, 18 cows were slaughtered and $\mathrm{SF}_{6}$ permeation tubes resident in the rumen of these animals were recovered. These recovered tubes were weighed using the same approach described previously for a further $6 \mathrm{wk}$ to determine postexperiment release rates.

\section{Chamber Design, Operation, and $\mathrm{CH}_{4}$ Measurements}

Two indirect open-circuit respiration chambers were used, which were made of insulated fenestrated panels mounted on a profiled floor, incorporating airlocks for entry and feeding. The total volume of $22 \mathrm{~m}^{3}$ was ventilated by suction pumps set at $75 \mathrm{~m}^{3} / \mathrm{h}$ giving approximately 3.5 air changes/h. Temperature and humidity control were achieved with air-conditioning units set at $15 \pm 1^{\circ} \mathrm{C}$ and $50 \pm 10 \%$ relative humidity, respectively. Chambers were operated under negative pressure (50 $\mathrm{N} / \mathrm{m}^{2}$ ) and exhaust air removed at 3 positions for volume measurement and gas analysis. Total air flow was measured by in-line turbine flow meters (GH Flow Automation Ltd., Andover, UK). Methane concentrations were measured by differential Luft analyzers (Analytical Development Co. Ltd., Hoddesdon, UK). Temperature, humidity, and atmospheric pressure were measured using Vaisala HUMICAP sensor probes and a Vaisala PTA 427 digital barometer (Delta-T Devices, Cambridge, UK), respectively. Results were collected via a 16-bit analog-digital converter (Strawberry Tree Model ACPC-16; Adept Scientific Micro System Ltd., Letchworth, UK) for 2 min from each chamber and the average values of the final minute logged to disk for postrun analysis giving 14 measurements/chamber per hour. The analysis train was designed to run automatically.

Prior to the beginning and at the end of each experimental period, the chambers were tested by comparing the amount of $\mathrm{CO}_{2}$ recorded by the gas analyzer $3 \mathrm{~h}$ after the release of a known quantity of pure $\mathrm{CO}_{2}$. The recovery was found to be almost $100 \%$ in all periods, with the exception of the testing carried out at the end of period 2 in chamber 2, when the air-conditioning unit was replaced. In this period, chamber and $\mathrm{SF}_{6}$ estimations measured in chamber 2 were corrected according to $\mathrm{CO}_{2}$ recovery rates $(95 \%)$.

Animals remained in the chamber for $96 \mathrm{~h}$, with $\mathrm{CH}_{4}$ measurements for the final $72 \mathrm{~h}$. These measurements account for all $\mathrm{CH}_{4}$ emissions produced by the animals, including those released through the rectum. 


\section{Calculation of $\mathrm{CH}_{4}$ Emissions from the Rectum}

Methane measurements in the chamber location by both the $\mathrm{SF}_{6}$ and respiration chamber techniques accounted for all sources of enteric $\mathrm{CH}_{4}$ emissions (mouth, nostrils, and rectum). However, the rectum $\mathrm{CH}_{4}$ source was not included in $\mathrm{CH}_{4}$ emissions estimated by the $\mathrm{SF}_{6}$ technique in the barn location, as occurs in grazing conditions. Therefore, $\mathrm{CH}_{4}$ emissions from the rectum were calculated by differences between $\mathrm{CH}_{4}$ outputs estimated by the $\mathrm{SF}_{6}$ technique when cows were housed in chambers (chamber location) and in digestibility units (barn location).

\section{Statistical Analysis}

All data were analyzed using the GenStat statistical package (Payne et al., 2007). The $\mathrm{CH}_{4}$ data collected in the chamber location by both the $\mathrm{SF}_{6}$ and respiration chamber techniques were used to validate the accuracy of the $\mathrm{SF}_{6}$ technique. The validation was undertaken using linear and quadratic regressions to develop relationships between $\mathrm{CH}_{4}$ emission measurements from the $\mathrm{SF}_{6}$ and respiration chamber techniques. A linear mixed model was also used to examine the effect of the measurement technique ( $\mathrm{SF}_{6}$ vs. respiration chamber) on $\mathrm{CH}_{4}$ emissions within individual periods throughout the whole study and interactions between the measurement techniques and experimental periods. The model used animal and cow pair as random effects and $\mathrm{SF}_{6}$ bolus release rate, chamber identification, period, $\mathrm{CH}_{4}$ measurement technique, and day of measurement as fixed effects.

The $\mathrm{CH}_{4}$ data measured by the $\mathrm{SF}_{6}$ technique in both chamber and barn locations were used to quantify $\mathrm{CH}_{4}$ emissions from the rectum. The data were analyzed using the same linear mixed model as described previously, with the exception that the effect of locations (chamber vs. barn) was used to replace the measurement technique and chamber identification was excluded from the model. Main effects of treatments and interactions were tested using a significance level of $P \leq 0.05$, and specific observed $P$-values are shown in the tables.

\section{RESULTS}

The present paper deals solely with the effect of $\mathrm{CH}_{4}$ measurement techniques ( $\mathrm{SF}_{6}$ vs. respiration chamber) and the proportion of $\mathrm{CH}_{4}$ emissions from the rectum over total $\mathrm{CH}_{4}$ emissions. The effects of concentrate level and yeast supplementation will be reported in a separate manuscript.

\section{Validation of $\mathrm{SF}_{6}$ Technique for Measurement of $\mathrm{CH}_{4}$ Emissions}

All data reported in this section were obtained when cows were housed in the respiratory chamber location. Methane emission measurements from $\mathrm{SF}_{6}$ and respiration chamber techniques, together with DMI and milk yield across all periods, are presented in Table 1. A large range of variation existed for each variable. For example, the difference in DMI between maximum and minimum values was $13.7 \mathrm{~kg} / \mathrm{d}$, and the maximum $\mathrm{CH}_{4}$ emissions were 2.1 and 2.2 times the minimum when measured by $\mathrm{SF}_{6}$ and chamber techniques, respectively. The $\mathrm{SF}_{6}$ technique overestimated $\mathrm{CH}_{4}$ emissions by $11 \%$ and had a higher variation coefficient than the respiration chamber technique (16.4 vs. $12.8 \%$ ).

The higher $\mathrm{CH}_{4}$ emission measurements from the $\mathrm{SF}_{6}$ technique compared with the respiration chamber technique were consistent from periods 1 to 4 (Table 2 ). However, this trend was influenced by experimental period, as an interaction $(P<0.01)$ existed between $\mathrm{CH}_{4}$ measurement technique and period of study on $\mathrm{CH}_{4}$ emission $(\mathrm{g} / \mathrm{d})$ and $\mathrm{CH}_{4}(\mathrm{~g} / \mathrm{kg})$ per unit of DMI or milk yield. However, the differences in $\mathrm{CH}_{4}$ emission measurements between the 2 techniques $\left(\mathrm{SF}_{6}\right.$ vs. respiration chamber) were not significant in the first 3 periods of the study, although in period 4 , these differences reached a significant level $(P<0.001)$. The period mean ratio of $\mathrm{CH}_{4}$ estimated by the $\mathrm{SF}_{6}$ tech-

Table 1. Data on mean and range of feed intake, milk yield, and methane $\left(\mathrm{CH}_{4}\right)$ emissions across the 4 periods of the study when cows were housed in the chamber location

\begin{tabular}{|c|c|c|c|c|}
\hline Item & Mean & SD & Minimum & Maximum \\
\hline DMI (kg/d) & 17.5 & 2.92 & 11.1 & 24.8 \\
\hline Milk yield $(\mathrm{kg} / \mathrm{d})$ & 22.9 & 6.47 & 6.3 & 43.0 \\
\hline $\mathrm{CH}_{4}$ measured by $\mathrm{SF}_{6}{ }^{1}(\mathrm{~g} / \mathrm{d})$ & 469 & 91.6 & 292 & 647 \\
\hline $\mathrm{CH}_{4}$ measured by chamber $(\mathrm{g} / \mathrm{d})$ & 422 & 71.2 & 275 & 577 \\
\hline $\mathrm{CH}_{4} / \mathrm{DMI}^{2}(\mathrm{~g} / \mathrm{kg})$ & 24.3 & 2.95 & 14.1 & 29.2 \\
\hline $\mathrm{CH}_{4} /$ milk yield $^{2}(\mathrm{~g} / \mathrm{kg})$ & 19.9 & 6.31 & 6.9 & 54.2 \\
\hline
\end{tabular}

${ }^{1}$ Sulfur hexafluoride technique.

${ }^{2} \mathrm{CH}_{4}$ emissions were measured by the respiration chamber technique. 
nique over those measured by the respiration chamber $\left[\left(\mathrm{SF}_{6}\right.\right.$ estimates $) /($ chamber estimates $\left.)\right]$ increased from periods 1 to 4 (1.06 to $1.22, P<0.001$; Table 2$)$. A similar comparison $\left\{\left[\left(\mathrm{SF}_{6}\right.\right.\right.$ estimates $)-$ (chamber estimates $)] /\left(\mathrm{SF}_{6}\right.$ estimates $\left.)\right\}$ using individual cow data of individual periods revealed a range of ratios from -0.13 to 0.35 , with the majority of data points being greater than 0 . The distribution of these ratios indicates that the majority of data measured in period 1 were in the low ranges, whereas in period 4 , data points were in the top ranges. The period mean ratios were $0.027,0.084$, 0.104 , and 0.158 in periods 1 to 4, respectively. Examining these ratios against the average period mean $\mathrm{CH}_{4}$ emissions (respiration chamber measurements), using individual cow data, revealed no relationship between these 2 data sets. This indicates that the overestimates of $\mathrm{CH}_{4}$ emissions by the $\mathrm{SF}_{6}$ technique were not influenced by the quantity of $\mathrm{CH}_{4}$ emissions of cows.

Data measured over the 4 periods of the study were pulled together to develop relationships between measurements of $\mathrm{SF}_{6}$ and respiration chamber techniques. The statistical analysis demonstrated that $\mathrm{SF}_{6}$ measurements of $\mathrm{CH}_{4}$ emissions (g/d) were reasonably related to respiration chamber measurements in a linear function (Figure $1 ; \mathrm{R}^{2}=0.69$ ). The linear relationship was improved when using $\mathrm{CH}_{4}$ emissions per unit of milk yield $\left(\mathrm{g} / \mathrm{kg}\right.$; Figure $\left.2 ; \mathrm{R}^{2}=0.88\right)$. However, when using $\mathrm{CH}_{4}$ emissions per kilogram of DMI, the linear relationship was poor (Figure $3 ; \mathrm{R}^{2}=0.49$ ) in comparison with the previous 2 relationships. However, this relationship could be improved when it was evaluated as a quadratic (Figure $3 ; \mathrm{R}^{2}=0.64$ ) rather than linear function.

\section{Calculation of $\mathrm{CH}_{4}$ Emissions from the Rectum}

All data reported in this section were obtained when cows were housed in both barn and chamber locations, with $\mathrm{CH}_{4}$ emissions measured by the $\mathrm{SF}_{6}$ technique. Mean enteric $\mathrm{CH}_{4}$ emission $(\mathrm{g} / \mathrm{d})$ and $\mathrm{CH}_{4}(\mathrm{~g} / \mathrm{kg})$ per unit of DMI or milk yield of cows in barn and chamber locations over the 4 periods, as estimated by the $\mathrm{SF}_{6}$ technique, are shown in Table 3. No interactions $(P>$ $0.05)$ were found between location of measurement and period of study. Day of measurement had no significant effect on $\mathrm{CH}_{4}$ emissions throughout the study. Methane estimates averaged from the barn location, both before and after being in respiratory chambers, for $\mathrm{d} 1,2$, and 3 , respectively, were 406, 413, and $420 \mathrm{~g} / \mathrm{d}$ [standard errors of the differences between means $($ SED $)=7.88, P$ $=0.11]$, and the corresponding estimates from chamber location were 420,416 , and $416 \mathrm{~g} / \mathrm{d}(\mathrm{SED}=2.89, P=$ $0.49)$.

No differences existed in $\mathrm{CH}_{4}$ emissions (413.2 vs. $415.9 \mathrm{~g} / \mathrm{d}, \mathrm{SED}=7.6, P=0.60)$ or $\mathrm{CH}_{4}$ emissions per unit of milk yield (21.4 vs. $21.6 \mathrm{~g} / \mathrm{kg}$, SED $=0.6$, $P=0.77)$ recorded in the barn location when compared with the chamber location. However, when $\mathrm{CH}_{4}$ emissions were expressed per unit of DMI $(\mathrm{g} / \mathrm{kg})$, measurements in the chamber location were $3 \%$ higher than those in the barn location (25.5 vs. $26.4 \mathrm{~g} / \mathrm{kg}$ of DMI, SED $=0.4, P=0.04)$. This indicates that $\mathrm{CH}_{4}$ emissions from the rectum were approximately $3 \%$ of that from the mouth, nostrils, and rectum. As stated previously, $\mathrm{SF}_{6}$ measurements of $\mathrm{CH}_{4}$ emissions in the chamber location include all sources of $\mathrm{CH}_{4}$ emissions, but in the barn location, a similar measurement as in a grazing situation, do not include $\mathrm{CH}_{4}$ emissions from the rectum.

\section{DISCUSSION}

\section{Validation of $\mathrm{SF}_{6}$ Technique}

Results of the present study support earlier work measuring $\mathrm{CH}_{4}$ emissions with the $\mathrm{SF}_{6}$ tracer technique, which indicate that the $\mathrm{SF}_{6}$ technique is associated with larger variation than respiration chamber measurements. For example, in the present study, coefficient of variation values for $\mathrm{CH}_{4}$ per unit of DMI for the $\mathrm{SF}_{6}$ and respiration chamber techniques were 14 and $11 \%$, respectively. The corresponding data for variability among animals between both techniques from the study of Grainger et al. (2007) with dairy cows were 20 and $18 \%$, and from the study of Pinares-Patiño et al. (2008a) with sheep were 18 and $7 \%$, respectively.

The major finding from the present study was an interaction between $\mathrm{CH}_{4}$ measurement technique $\left(\mathrm{SF}_{6}\right.$ vs. respiration chamber) and period of the study. The $\mathrm{CH}_{4}$ emissions estimated by the $\mathrm{SF}_{6}$ technique were similar to those measured by the respiration chamber technique in the first 3 periods, but the $\mathrm{SF}_{6}$ technique significantly overestimated $\mathrm{CH}_{4}$ emissions in period 4 . These results suggest that the $\mathrm{SF}_{6}$ technique is a reasonably accurate method for estimating enteric $\mathrm{CH}_{4}$ emissions from dairy cows provided the permeation tubes have not been resident in the rumen for prolonged periods.

Most of the studies that compared the $\mathrm{SF}_{6}$ tracer technique with other techniques for measuring $\mathrm{CH}_{4}$ emissions have reported no significant differences between methods. Of these studies, only 2 were carried out in lactating dairy cows that have higher intakes and $\mathrm{CH}_{4}$ emissions. McCourt et al. (2008), although reporting a good correlation between $\mathrm{CH}_{4}$ emissions obtained by the $\mathrm{SF}_{6}$ and respiration chamber techniques $\left(\mathrm{R}^{2}=\right.$ 0.76 ), found that $\mathrm{CH}_{4}$ measured using the $\mathrm{SF}_{6}$ technique was $75 \%$ of that measured using the respiration chamber method. In contrast, Grainger et al. (2007) reported that total $\mathrm{CH}_{4}$ emissions measured using res- 
Table 2. Comparison of methane $\left(\mathrm{CH}_{4}\right)$ emissions measured by the sulfur hexafluoride $\left(\mathrm{SF}_{6}\right)$ and respiration chamber techniques when cows were housed in the chamber location over the 4 periods of the study

\begin{tabular}{|c|c|c|c|c|c|c|c|c|c|c|c|c|}
\hline \multirow[b]{2}{*}{ Item } & \multicolumn{2}{|c|}{ Period 1} & \multicolumn{2}{|c|}{ Period 2} & \multicolumn{2}{|c|}{ Period 3} & \multicolumn{2}{|c|}{ Period 4} & \multirow[b]{2}{*}{ SED $^{1}$} & \multicolumn{3}{|c|}{$P$-value } \\
\hline & $\mathrm{SF}_{6}$ & Chamber & $\mathrm{SF}_{6}$ & Chamber & $\mathrm{SF}_{6}$ & Chamber & $\mathrm{SF}_{6}$ & Chamber & & Technique & Period & Interaction \\
\hline DMI $(\mathrm{kg} / \mathrm{d})$ & \multicolumn{2}{|r|}{16.0} & \multicolumn{2}{|c|}{18.2} & \multicolumn{2}{|c|}{16.4} & \multicolumn{2}{|c|}{15.6} & 1.21 & - & 0.001 & - \\
\hline $\mathrm{CH}_{4}(\mathrm{~g} / \mathrm{d})$ & 381 & 366 & 492 & 444 & 453 & 403 & 447 & 369 & 31.2 & $<0.001$ & $<0.001$ & 0.022 \\
\hline $\mathrm{CH}_{4} / \mathrm{DMI}(\mathrm{g} / \mathrm{kg})$ & 24.5 & 23.6 & 28.8 & 26.3 & 26.0 & 23.3 & 27.5 & 22.6 & 1.93 & $<0.001$ & 0.001 & 0.002 \\
\hline $\mathrm{CH}_{4} /$ milk yield $(\mathrm{g} / \mathrm{kg})$ & 21.1 & 20.5 & 29.9 & 27.6 & 15.4 & 12.8 & 15.5 & 11.4 & 2.22 & $<0.001$ & $<0.001$ & 0.047 \\
\hline $\mathrm{CH}_{4}$ ratio $\left(\mathrm{SF}_{6} /\right.$ chamber $)$ & \multicolumn{2}{|c|}{1.06} & \multicolumn{2}{|c|}{$1.08^{29.9}$} & \multicolumn{2}{|c|}{1.09} & \multicolumn{2}{|c|}{1.22} & 0.076 & - & $<0.001$ & - \\
\hline
\end{tabular}

${ }^{1} \mathrm{SED}=$ standard errors of the differences between means.

Table 3. Effects of location (where cows were housed) of the sulfur hexafluoride $\left(\mathrm{SF}_{6}\right)$ measurement on methane $\left(\mathrm{CH}_{4}\right)$ emissions over the 4 periods of the study

\begin{tabular}{|c|c|c|c|c|c|c|c|c|c|c|c|c|c|c|c|c|}
\hline \multirow[b]{2}{*}{ Item } & \multicolumn{3}{|c|}{ Period 1} & \multicolumn{3}{|c|}{ Period 2} & \multicolumn{3}{|c|}{ Period 3} & \multicolumn{3}{|c|}{ Period 4} & \multirow[b]{2}{*}{$\mathrm{SED}^{1}$} & \multicolumn{3}{|c|}{$P$-value } \\
\hline & $\begin{array}{c}\text { Before } \\
\mathrm{RC}^{2}\end{array}$ & $\mathrm{RC}$ & $\begin{array}{c}\text { After } \\
\text { RC }\end{array}$ & $\begin{array}{c}\text { Before } \\
\text { RC }\end{array}$ & $\mathrm{RC}$ & $\begin{array}{c}\text { After } \\
\text { RC }\end{array}$ & $\begin{array}{c}\text { Before } \\
\text { RC }\end{array}$ & $\mathrm{RC}$ & $\begin{array}{c}\text { After } \\
\text { RC }\end{array}$ & $\begin{array}{c}\text { Before } \\
\text { RC }\end{array}$ & $\mathrm{RC}$ & $\begin{array}{c}\text { After } \\
\text { RC }\end{array}$ & & Location & Period & Interaction \\
\hline DMI (kg/d) & 17.0 & 16.6 & 17.1 & 17.9 & 18.1 & 18.7 & 16.4 & 15.4 & 16.3 & 15.1 & 14.9 & 15.8 & 1.07 & 0.003 & $<0.001$ & 0.77 \\
\hline $\mathrm{CH}_{4}(\mathrm{~g} / \mathrm{d})$ & 339 & 365 & 330 & 506 & 511 & 498 & 404 & 405 & 417 & 443 & 421 & 434 & 38.4 & 0.57 & $<0.001$ & 0.27 \\
\hline $\mathrm{CH}_{4} / \mathrm{DMI}(\mathrm{g} / \mathrm{kg})$ & 21.5 & 23.1 & 20.7 & 28.8 & 28.8 & 28.2 & 24.9 & 26.5 & 26.0 & 29.1 & 28.5 & 27.5 & 2.35 & 0.019 & $<0.001$ & 0.35 \\
\hline $\mathrm{CH}_{4} / \mathrm{MY}^{3}(\mathrm{~g} / \mathrm{kg})$ & 17.3 & 18.4 & 17.5 & 26.1 & 27.1 & 26.1 & 20.6 & 20.9 & 20.5 & 24.0 & 21.7 & 23.1 & 3.74 & 0.60 & $<0.001$ & 0.79 \\
\hline
\end{tabular}

${ }^{1} \mathrm{SED}=$ standard errors of the differences between means.

${ }^{2} \mathrm{RC}=$ respiration chambers.

${ }^{3} \mathrm{MY}=$ milk yield. 


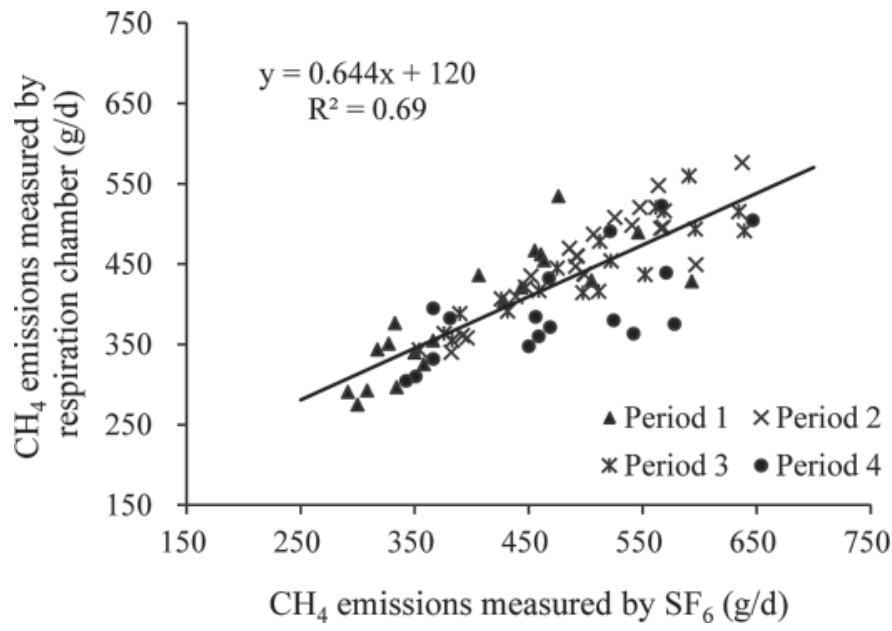

Figure 1. The relationship between methane $\left(\mathrm{CH}_{4}\right)$ emissions measured simultaneously by respiration chamber and sulfur hexafluoride $\left(\mathrm{SF}_{6}\right)$ techniques for individual cows when animals were housed in the chamber location.

piration chamber and $\mathrm{SF}_{6}$ techniques were similar, with $\mathrm{SF}_{6}$ estimates being slightly higher $(2 \%)$ than respiration chamber estimates.

In the present study, the overestimates $(11 \%)$ of $\mathrm{CH}_{4}$ emissions by the $\mathrm{SF}_{6}$ technique compared with the respiration chamber technique were higher than that of Grainger et al. (2007). Nevertheless, the statistical analysis of data from all 4 periods in the present study found a reasonable relationship between the $\mathrm{SF}_{6}$ and respiration chamber measurements of $\mathrm{CH}_{4}$ emissions when expressed as total $\mathrm{CH}_{4}$ emissions $(\mathrm{g} / \mathrm{d})$ or as $\mathrm{CH}_{4}$ emissions per unit of milk yield or DMI $(\mathrm{g} / \mathrm{kg})$. These

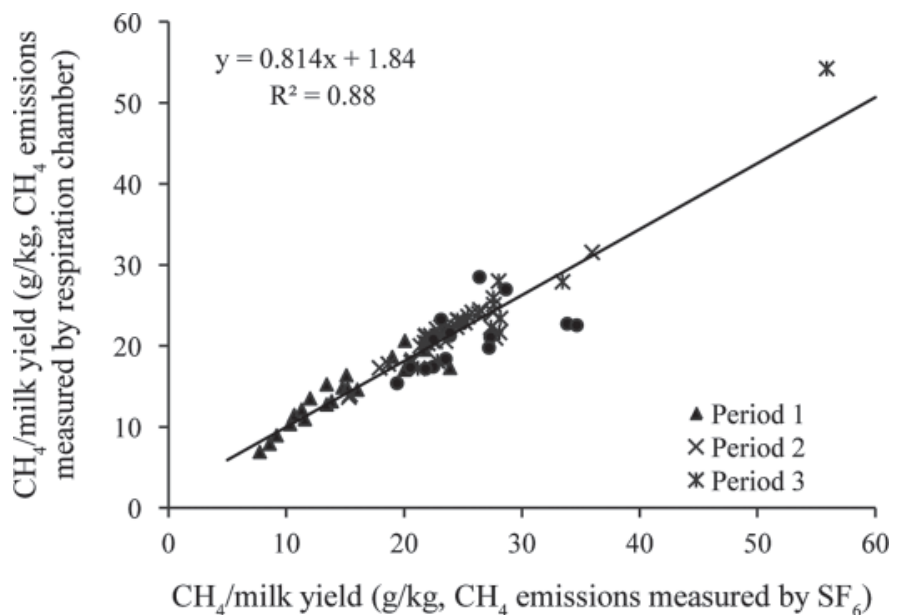

Figure 2. The relationship between methane $\left(\mathrm{CH}_{4}\right)$ emissions per unit of milk yield measured simultaneously by respiration chamber and sulfur hexafluoride $\left(\mathrm{SF}_{6}\right)$ techniques for individual cows when animals were housed in the chamber location.

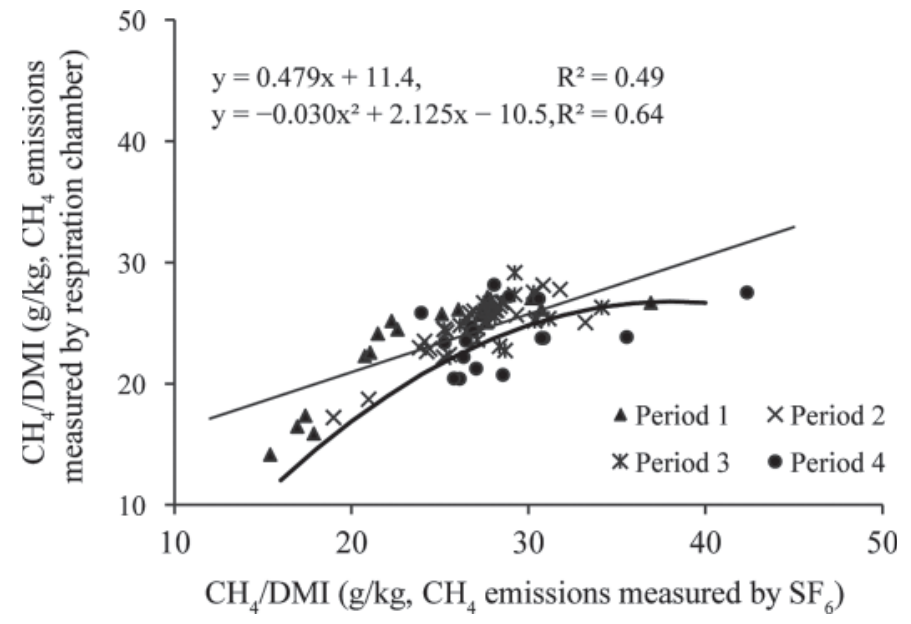

Figure 3. The relationships between methane $\left(\mathrm{CH}_{4}\right)$ emissions per unit of DMI measured simultaneously by respiration chamber and sulfur hexafluoride $\left(\mathrm{SF}_{6}\right)$ techniques for individual cows when animals were housed in the chamber location.

relationships provide approaches to correcting the overestimates of $\mathrm{CH}_{4}$ emissions by the $\mathrm{SF}_{6}$ technique when used in grazing cattle. A similar linear relationship was also reported by McCourt et al. (2008).

A couple of factors may have contributed to the higher $\mathrm{CH}_{4}$ estimation obtained by the $\mathrm{SF}_{6}$ technique relative to the respiration chamber technique in the current study. The first has to do with the reduction of the release rates of $\mathrm{SF}_{6}$ over time. Immediately after the completion of the last period, a recovery trial was undertaken to recover permeation tubes from the rumen of cows used in the present study. Recovered tubes $(\mathrm{n}=18)$ were weighed for 6 wk to determine postexperimental release rates (Figure 4). Postrecovery release rates of all tubes were, on average, $66 \%$ of the preexperimental release rates, with the majority of tubes being between 70 to $90 \%$ of the original release rates. This indicates that, in the present study, $\mathrm{SF}_{6}$ release rates of the permeation tubes were decreased with the increased residence time of permeation tubes in the rumen. Thus, the decrease in the release rates resulted in an overestimation of $\mathrm{CH}_{4}$ emissions by the $\mathrm{SF}_{6}$ technique as the study progressed. Relating $\mathrm{CH}_{4}$ measurement wk (x) to the period mean ratio of $\mathrm{SF}_{6}$ estimate/respiration chamber estimate $(\%, y)$, when cows were housed in the chamber location, demonstrated that the ratio increased in a curvilinear relationship (y $\left.=0.0216 \mathrm{x}^{2}-0.0093 \mathrm{x}+104, \mathrm{R}^{2}=0.96\right)$.

Several previous studies have also reported that the $\mathrm{SF}_{6}$ release rates in permeation tubes were slowly decreased over time, rather than remaining constant as the technique assumes (Ulyatt et al., 1999; Lassey et al., 2001; Pinares-Patiño et al., 2008a). Lassey et al. (2001) 


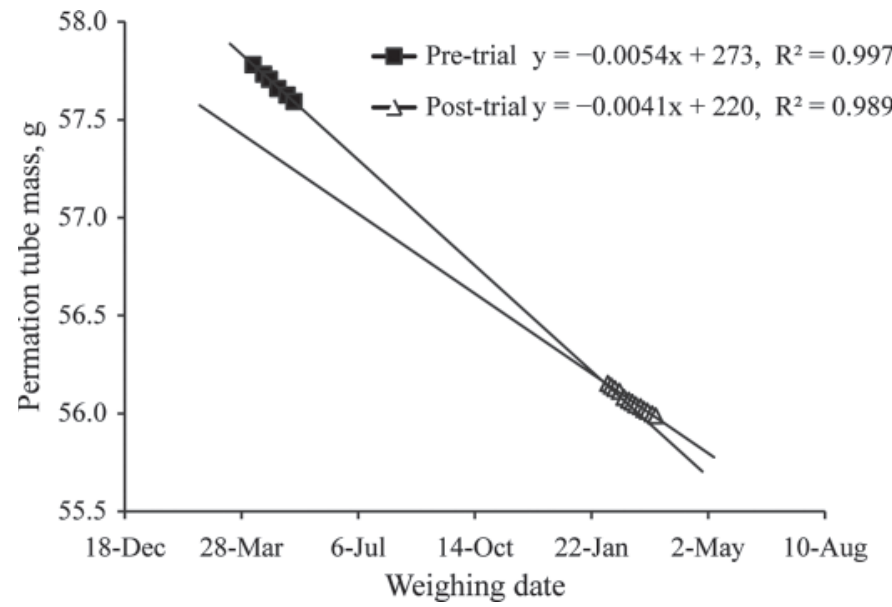

Figure 4. Mean preexperimental and postexperimental weights of sulfur hexafluoride permeation tubes used in the present study, with their respective linear regressions fitted and extrapolated to cover the duration of the study.

demonstrated that the rate of mass loss in permeation tubes recovered from sheep or maintained in laboratory as controls decreased slowly with time. Pinares-Patiño et al. (2008a) conducted 2 trials with sheep to evaluate the accuracy of the $\mathrm{SF}_{6}$ technique when permeation tubes were deployed in the rumen for 30 or $250 \mathrm{~d}$ at the time of measurement. In the trial with the older permeation tubes the postrecovery release rates were smaller than the preexperimental release rates. Using data from 9 studies, Grainger et al. (2010) presented a linear and positive relationship between the duration of permeation tubes in the rumen and the ratios of $\mathrm{SF}_{6}$ over respiration chamber measurements of $\mathrm{CH}_{4}$ emissions. In the light of evidence obtained in the present study and the trial of Grainger et al. (2010), it appears that the decrease in $\mathrm{SF}_{6}$ release rates of permeation tubes in the rumen of cattle and sheep increases as time elapses.

Two previous studies have compared 2 levels (means of 2.9 and of $7.3 \mathrm{mg} / \mathrm{d}$; Vlaming et al., 2007) and 2 ranges (range of 2.2 to 3.6 and 2.6 to $5.7 \mathrm{mg} / \mathrm{d}$; Pinares-Patiño et al., 2008b) of $\mathrm{SF}_{6}$ release rates in cattle. Authors concluded that a positive relationship existed between $\mathrm{SF}_{6}$ release rates and estimated $\mathrm{CH}_{4}$ emission. However, this effect is controllable by narrowing the range of release rates of permeation tubes used in any single experiment and balancing release rates between treatments (Pinares-Patiño and Clark, 2008). In the current study, the $\mathrm{SF}_{6}$ release rate of permeation tubes ranged from 4.1 to $6.4 \mathrm{mg} / \mathrm{d}$, with a mean \pm standard deviation of $5.4 \pm 0.7 \mathrm{mg} / \mathrm{d}$. These release rates, although in a narrow range, were higher than the release rates reported for dairy cows by McCourt (2007; 1.2 to $1.9 \mathrm{mg} / \mathrm{d})$ and Grainger et al. $(2007$; mean $=3.7$ $\mathrm{mg} / \mathrm{d}, \mathrm{SD}=0.7)$, and for beef cows by McGinn et al. (2006; 4.3 to $4.9 \mathrm{mg} / \mathrm{d}$ ). Therefore, it is plausible that the permeation tubes with high release rates used in the present study might also contribute to the overestimates of $\mathrm{CH}_{4}$ emission by the $\mathrm{SF}_{6}$ technique.

A further factor that might influence the accuracy of $\mathrm{CH}_{4}$ estimates by the $\mathrm{SF}_{6}$ technique was the sampling tube used in the current study. A small experiment was carried out during the final period of the present study to evaluate the effect of different sampling tubes on the results of the $\mathrm{SF}_{6}$ technique. This trial was carried out in period 4 using 19 cows when housed in digestibility units (before respiratory chamber location). When applying the $\mathrm{SF}_{6}$ technique for 3 consecutive days, each cow was fitted with a modified halter holding 3 different sampling tubes, taking air from the nose area of the cow to the canister. The 3 sampling tubes were used to test the effects of the diameter of the sampling tube and the distance of the capillary (used to control the air flow rate) from the sampling point (just above the nose of animal). Tube A had the capillary located close to the sampling point, with a sampling tube diameter of $6.35 \mathrm{~mm}$; tube B had the capillary located close to the canister, with a sampling tube diameter of 3.175 $\mathrm{mm}$; and tube $\mathrm{C}$ had the capillary located close to the canister, with a sampling tube diameter of $6.35 \mathrm{~mm}$. All sampling tubes had a length of $2 \mathrm{~m}$ and all canisters were located on top of the crush. The $\mathrm{CH}_{4}$ estimations obtained from tube A were lower than those from tubes $\mathrm{B}$ and $\mathrm{C}(434$ vs. 444 vs. $451 \mathrm{~g} / \mathrm{d}, \mathrm{SED}=7.18, P$ $<0.001)$. This small trial demonstrated that the location of the capillary in sampling tubes can affect the estimate of $\mathrm{CH}_{4}$ emissions (i.e., a sampling tube with the capillary located close to the sampling point would result in a lower $\mathrm{CH}_{4}$ estimate). It is speculated that a sampling tube with the capillary (used to restrict the sucking rate) located close to the evacuated canister would leave some breath samples to be trapped in the sampling tube. This may alter the ratios of $\mathrm{SF}_{6}$ over $\mathrm{CH}_{4}$ gases that pass the capillary into the canister, because $\mathrm{SF}_{6}$ is heavier than $\mathrm{CH}_{4}$, and $\mathrm{CH}_{4}$ would travel faster than $\mathrm{SF}_{6}$ to reach the capillary, as the effusion rate of $\mathrm{CH}_{4}$ is 3 times faster than that of $\mathrm{SF}_{6}$. This would result in increased estimates of $\mathrm{CH}_{4}$ emissions. The sampling tube used in the present study was tube C. Different sampling tubes used in previously published work may have contributed to the variation in $\mathrm{CH}_{4}$ emissions estimated by the $\mathrm{SF}_{6}$ technique.

\section{Methane Emissions from the Rectum}

One of the aims of the current study was to evaluate the proportion of $\mathrm{CH}_{4}$ released through the rectum compared with total $\mathrm{CH}_{4}$ emissions including fore- and 
hindgut emissions. This information can then be used to adjust the $\mathrm{SF}_{6}$ technique measurements for grazing cattle and sheep, because these measurements do not include $\mathrm{CH}_{4}$ emissions from the rectum. To do this, $\mathrm{CH}_{4}$ emission data estimated by the $\mathrm{SF}_{6}$ technique were used when cows were housed in chamber and barn locations. The measurements in the chamber location include all sources of enteric $\mathrm{CH}_{4}$ emissions (mouth, nostrils, and rectum) but in the barn location, they do not account for the emissions from the rectum (similar to a grazing situation). It could be argued that because the overestimate of $\mathrm{CH}_{4}$ emissions from the $\mathrm{SF}_{6}$ technique appeared to increase with time, the best comparison of the 2 locations (chamber vs. barn) would appear to be in period 1 when the $\mathrm{SF}_{6}$ and respiration chamber techniques were most similar in estimating $\mathrm{CH}_{4}$. However, no interactions were observed between period of the study and location of the measurement, so the use of data from all periods should be more robust.

Results obtained indicate that when $\mathrm{CH}_{4}$ emissions are expressed per unit of DMI, $\mathrm{CH}_{4}$ emitted by the rectum accounts for $3 \%$ of total $\mathrm{CH}_{4}$ production. This proportion is marginally higher than that reported by Murray et al. (1976) with sheep using the isotopic technique $(<2 \%)$ and is coherent with the expectation that $\mathrm{SF}_{6}$ tracer estimates should be slightly lower than actual total $\mathrm{CH}_{4}$ emissions. The proportion of $\mathrm{CH}_{4}$ emissions from the rectum should be associated with the extent of enteric fermentation in the hindgut (e.g., availability of fiber contents). Evidence indicated that the agreement in estimates of $\mathrm{CH}_{4}$ emissions between the $\mathrm{SF}_{6}$ and respiration chamber techniques improved when cattle were fed at a restricted level of intake (McGinn et al., 2006). The restricted feeding would reduce the outflow rate from the rumen and result in less OM (e.g., fiber) available in the hindgut, thus having less postruminal $\mathrm{CH}_{4}$ production. Further research is needed to quantify the magnitude of $\mathrm{CH}_{4}$ released by the rectum under conditions that affect rumen outflow rates to a higher degree than those used in the present study.

\section{CONCLUSIONS}

Agreement was observed between the $\mathrm{SF}_{6}$ tracer and respiration chamber techniques for measuring $\mathrm{CH}_{4}$ emissions over the first 3 periods of the present study. However, differences between the techniques increased with time, resulting in an overestimation of $\mathrm{CH}_{4}$ emissions by the $\mathrm{SF}_{6}$ technique. This may be largely related to the decreased $\mathrm{SF}_{6}$ release rate of the permeation tubes after a prolonged period of residence in the rumen. The present study also found that $\mathrm{CH}_{4}$ emissions from the rectum were, on average, $3 \%$ of $\mathrm{CH}_{4}$ emis- sions from all sources of enteric fermentation (mouth, nostrils, and rectum). A range of linear and quadratic relationships have been developed in the present study to correct the limitations of the $\mathrm{SF}_{6}$ technique using $\mathrm{CH}_{4}$ emission estimates from the $\mathrm{SF}_{6}$ and respiration chamber techniques. These findings indicate that the $\mathrm{SF}_{6}$ technique can be a reasonably accurate method to quantify enteric $\mathrm{CH}_{4}$ emissions for grazing dairy cows, and that $\mathrm{SF}_{6}$ measurements should be adjusted for $\mathrm{CH}_{4}$ emissions from the rectum because these emissions are not included when the $\mathrm{SF}_{6}$ technique is used.

\section{ACKNOWLEDGMENTS}

The authors acknowledge A. Gautier, S. Hunter, S. Martin, K. McKinley, and A. Stewart [Agri-Food and Biosciences Institute (AFBI), Hillsborough, Co Down, UK] for their assistance throughout the study. This study was funded by the Department of Agriculture and Food of the Republic of Ireland (Dublin, Ireland) through the Research Stimulus Fund program (RSF 07-517) and Department of Agriculture and Rural Development of Northern Ireland (Belfast, UK).

\section{REFERENCES}

Boadi, D. A., K. M. Wittenberg, and A. D. Kennedy. 2002. Validation of the sulfur hexafluoride $\left(\mathrm{SF}_{6}\right)$ tracer gas technique for measurement of methane and carbon dioxide production by cattle. Can. J. Anim. Sci. 82:125-131.

Grainger, C., T. Clarke, S. M. McGinn, M. J. Auldist, K. A. Beauchemin, M. C. Hannah, G. C. Waghorn, H. Clark, and R. J. Eckard. 2007. Methane emissions from dairy cows measured using the sulfur hexafluoride $\left(\mathrm{SF}_{6}\right)$ tracer and chamber techniques. J. Dairy Sci. 90:2755-2766.

Grainger, C., R. Williams, T. Clarke, A. D. G. Wright, and R. J. Eckard. 2010. Supplementation with whole cottonseed causes longterm reduction of methane emissions from lactating dairy cows offered a forage and cereal grain diet. J. Dairy Sci. 93:2612-2619.

Johnson, K., M. Huyler, H. Westberg, B. Lamb, and P. Zimmerman. 1994. Measurement of methane emissions from ruminant livestock using a $\mathrm{SF}_{6}$ tracer technique. Environ. Sci. Technol. 28:359-362.

Johnson, K. A., H. H. Westberg, J. J. Michal, and M. W. Cossalman. 2007. The $\mathrm{SF}_{6}$ tracer technique: Methane measurement from ruminants. Pages 33-67 in Measuring Methane Production from Ruminants. H. P. S. Makkar and P. E. Vercoe, ed. Springer, Dordrecht, the Netherlands.

Lassey, K. R., C. F. Walker, A. M. S. McMillan, and M. J. Ulyatt. 2001. On the performance of SF6 permeation tubes used in determining methane emission from grazing livestock. ChemosphereGlobal Change Sci. 3:367-376.

McCourt, A. R. 2007. Factors influencing methane emissions from ruminants and possible mitigation strategies with reference to dairy cattle. PhD Thesis. Queen's University of Belfast, Belfast, UK.

McCourt, A. R., T. Yan, and S. Mayne. 2008. Validation of the sulfur hexafluoride $\left(\mathrm{SF}_{6}\right)$ tracer technique as a method of predicting methane output from dairy cows. Page 120 in Proc. Br. Soc. Anim. Sci., Scarborough, UK. Br. Soc. Anim. Sci., Edinburgh, UK.

McGinn, S. M., K. A. Beauchemin, A. D. Iwaasa, and T. A. McAllister. 2006. Assessment of the sulfur hexafluoride $\left(\mathrm{SF}_{6}\right)$ tracer technique for measuring enteric methane emissions from cattle. J. Environ. Qual. 35:1686-1691. 
Murray, R. M., A. M. Bryant, and R. A. Leng. 1976. Rates of production of methane in the rumen and large intestine of sheep. Br. J. Nutr. 36:1-14.

Payne, R. W., D. A. Murray, S. A. Harding, D. B. Baird, and D. M. Soutar. 2007. GenStat for Windows. 10th ed. Introduction. VSN International, Hemel Hempstead, UK.

Pinares-Patiño, C. S., and H. Clark. 2008. Reliability of the sulfur hexafluoride tracer technique for methane emission measurement from individual animals: An overview. Aust. J. Exp. Agric 48:223-229.

Pinares-Patiño, C. S., C. W. Holmes, K. R. Lassey, and M. J. Ulyatt 2008a. Measurement of methane emission from sheep by the sulfur hexafluoride tracer technique and by the calorimetric chamber: Failure and success. Animal 2:141-148.

Pinares-Patiño, C. S., K. R. Lassey, R. J. Martin, G. Molano, M Fernandez, S. MacLean, E. Sandoval, D. Luo, and H. Clark. 2011. Assessment of the sulphur hexafluoride $\left(\mathrm{SF}_{6}\right)$ tracer technique us- ing respiration chambers for estimation of methane emissions from sheep. Anim. Feed Sci. Technol. 166:201-209.

Pinares-Patiño, C. S., A. Machmüller, G. Molano, A. Smith, J. B. Vlaming, and H. Clark. 2008b. The $\mathrm{SF}_{6}$ tracer technique for measurements of methane emission from cattle-Effect of tracer permeation rate. Can. J. Anim. Sci. 88:309-320.

Ulyatt, M. J., S. K. Baker, G. J. McCrabb, and K. R. Lassey. 1999. Accuracy of $\mathrm{SF}_{6}$ tracer technology and alternatives for field measurements. Aust. J. Agric. Res. 50:1329-1334.

Vlaming, J. B., I. M. Brookes, S. O. Hoskin, C. S. Pinares-Patiño, and H. Clark. 2007. The possible influence of intra-ruminal sulphur hexafluoride release rates on calculated methane emissions from cattle. Can. J. Anim. Sci. 87:269-275.

Wright, A. D. G., P. Kennedy, C. J. O'Neill, A. F. Toovey, S. Popovski, S. M. Rea, C. L. Pimm, and L. Klein. 2004. Reducing methane emissions in sheep by immunization against rumen methanogens. Vaccine 22:3976-3985. 